\title{
Effects of Egg Coverages on Storage and Pre-incubation Periods in Broiler Breeder Eggs
}

\author{
Ezzat K. I. Al-Samrai ${ }^{1}$ and Ammar A. Tawfeeq ${ }^{2 *}$ \\ ${ }^{I}$ Vocational Education Department, Anbar, Ministry of Education, Iraq \\ ${ }^{2}$ College of Applied Sciences, Heet, University of Anbar, Iraq \\ *Corresponding author's email: ammarabta@uoanbar.edu.iq; ORCID: 0000-0002-0369-0129
}

Received: 26 October 2021

Accepted: 08 December 2021

\begin{abstract}
The quality of the hatching eggs decreases when the storage period is prolonged leading to a loss of water from the egg. The current study aimed to assess the effects of coverage, storage, and pre-incubation on egg characteristics of broiler breeders. A total of 360 broiler breeder eggs (Ross, 308) used in the current study were randomly distributed in a three-factorial experiment $(2 \times 2 \times 3)$. The study included two treatments for coverage (covered with nylon and uncovered), two treatments ( 4 and 7 days) for storage, and three treatments $(0,4$, and 8 hours) for pre-incubation. For each treatment, there were three replicates (10 eggs in each replicate). The eggs were pre-incubated at $37.5^{\circ} \mathrm{C}$ $\left(99.5^{\circ} \mathrm{F}\right)$ and $85 \%$ relative humidity, while the storage temperature was $15-18^{\circ} \mathrm{C}$ and $55-60 \%$ relative humidity. The results showed that the hatchability from fertile eggs significantly increased in covered eggs, compared to uncovered ones. However, the characteristics of the shell and the shape index were not significantly affected by the three factors. Yolk high and yolk index significantly decreased in eggs stored for seven days, compared to the eggs stored for four days. Eggs coverage during storage significantly reduced moisture loss on the first and seventh days of egg incubation, compared to uncovered eggs. In addition, the lowest significant value of moisture loss appeared at incubation days of 7, 15, and 18 for covered eggs with 4 days of storage but without pre-incubation. In conclusion, the results of the present study indicated that the coverage decreased moisture loss during egg storage. Furthermore, the interaction between coverage factor and pre-incubation factor indicated the albumin high increased significantly in eggs covered and pre-incubated for 8 hours.
\end{abstract}

Keywords: Coverage, Egg, Moisture loss, Pre-incubation, Storage

\section{INTRODUCTION}

The storage of hatching eggs is a common and necessary process in the poultry industry. The length of the egg storage period, which ranges from a few days to several weeks, depends on several factors, including the age of the breeders' flocks, the capacity of the hatching incubators, and the market demand for broiler chicks (Özlü et al, 2021; Tesarova et al, 2021). The quality of the hatching eggs decreases when the storage period is prolonged, which leads to a loss of water from the egg (van den Brand et al., 2008), a decrease in the egg weight, shell weight, albumin high, haugh unit, and the yolk index, but in return, it results in a rapid increase in the $\mathrm{pH}$ of the albumin and the yolk (Samli et al., 2005). Degradation of egg albumin viscosity (Khan et al., 2014) is due to the increased liquidity that comes from the decomposition of carbonic acid into water and $\mathrm{CO}_{2}$ (Nasri et al., 2020) as well as the gas exchange that takes place between the embryo and its external environment (Brake et al., 1997;
Rocha et al., 2013). Bloom et al. (1998) explained that the prolonged period of hatching egg storage may lead to shrinkage of blastodermal cells by either apoptosis or unplanned programmed death due to the increasing number of dead cells (Mather and Laughlin, 1979; Fasenko, 2007). Al-Samrai (2012) found that the 14 days storage process after the pre-incubation of the eggs for 12 hours led to a clear deterioration in the yolk characteristics as the yolk heigh decreased significantly, compared to the egg yolk stored for 4 days after pre-incubation for 12 hours.

Several studies have indicated that a storage period of more than seven days reduces the hatchability, and the harmful effect of prolonged storage increases even more if the storage temperature is higher than $21^{\circ} \mathrm{C}$ (Ruiz and Lunam, 2002). The reason is that this temperature is considered the physiological zero degrees for broiler embryos, under which no embryonic development occurs during storage (Fasenko, 2007), and it is the required 
temperature for the growth of the blastoderm. Therefore, some researchers have indicated that the hatching eggs can be kept at temperatures that may reach $28^{\circ} \mathrm{C}$ if the storage period is less than four days, but if the storage period is up to seven days, the storage temperature must be reduced to $15^{\circ} \mathrm{C}$. If the storage period is longer than seven days, the storage temperature should not exceed $11^{\circ} \mathrm{C}$ (Butler, 1990).

Pre-incubation is the process of exposing the hatching eggs to the same normal incubation conditions in the incubators of a temperature $\left(37.5^{\circ} \mathrm{C}, 99^{\circ} \mathrm{F}\right)$ and relative humidity of $85 \%$, turning then for 4-12 hours (Reijrink et al., 2009), then, the eggs are stored at a temperature of $18^{\circ} \mathrm{C}$ and relative humidity of 55-60\% (Fasenko, 2007). This process aims to accelerate the development of the embryo into stages helping it to withstand a long period of storage without causing mortality. Reijrink et al. (2009) confirmed that the pre-incubation process reduces the deterioration in the internal quality traits of the egg, compared to the stored eggs without pre-incubation for varying periods. It should be noted that the thermal stimulation of eggs through pre-incubation accelerates the cellular metabolism, as the energy from the carbohydrates present in the egg is relied upon in the first place and then the yolk sac would be consumed (Kollmann Filho et al., 2020).

Water is lost from hatching eggs through evaporation during storage, the rate of water loss is affected by several factors, including relative humidity, temperature, and porosity of the shell and the movement of air has a slight effect on the rate of water loss. Moreover, many researchers noted the hatchability is better when less water is lost from the egg (Meijerhof, 1992). Packaging eggs with bags have an advantageous effect on egg quality as it prevents loss of moisture and $\mathrm{CO}_{2}$ (Reijrink, 2010), and reduces the gas exchange between the egg and the external environment (Proudfoot, 1964), which leads to slower degradation of albumin quality and keeps the $\mathrm{pH}$ from rising (Becker, 1964; Proudfoot and Hamilton, 1990; Brake et al., 1997). The present study aimed to evaluate the possibility of reducing the negative impact of storage on the quality of hatching eggs through pre-incubation and coverage, as well as reducing moisture loss in broiler breeders' eggs.

\section{MATERIALS AND METHODS}

\section{Ethical approval}

According to Directive 2010/63/EU of 22 September 2010, and recommendation of the European Commission
2007/526/CE, the hatching eggs in the current study were used for experimental and other scientific purposes.

\section{Experiment design}

A total of 360 eggs from broiler breeders (Ross, 308) were used in the current study brought from the broiler breeder houses in the College of Agriculture at the University of Anbar, Iraq (the broiler breeders age at the time of egg collection was 33 weeks). The eggs were then randomly distributed in a three-factorial experiment $(2 \times 2$ $\times 3$ ). The study included two treatments for coverage (covered with nylon and uncovered), two treatments for storage (4 and 7 days), and three treatments for preincubation $(0,4$, and 8 hours). For each treatment, there were three replicates (10 eggs in each replicate). The eggs were brought in two stages (180 eggs in each stage) with a three-day interval. The eggs of the first group, which were scheduled to be stored for 7 days at noon, were collected and entered into pre-incubation and storage the next day. The second group of eggs was scheduled to be stored for 4 days and they were then collected three days after the first stage of collection. The eggs of the secong group were treated by the same operations performed on the first group. The first group was stored for 7 days and the second for 4 days. The first six groups were divided into two groups, three of which were subjected to preincubation (for 0,4 , and 8 hours) and then stored in the refrigerated storage room, while the other three were exposed to the same pre-incubation hours, covered with nylon for food preservation (Falcon), and then stored for 7 days in a refrigerated storage room at a temperature of 15$18^{\circ} \mathrm{C}$. After three days, eggs were brought from the same flock and the same house. Moreover, the performed operations were the same as the ones carried out on eggs stored for 7 days. The eggs were pre-incubated $(0,4$, and 8 hours) at $37.5^{\circ} \mathrm{C}\left(99.5^{\circ} \mathrm{F}\right)$ and $85 \%$ relative humidity, while the storage temperature applying the same time intervals was $15-18^{\circ} \mathrm{C}$ and $55-60 \%$ relative humidity. Then, all eggs were inserted into the incubator for 21 days to study the effect of coverage, storage, and pre-incubation on moisture loss.

\section{Egg quality parameters}

After the eggs collecting in the two stages, all eggs were weighed and the longitudinal and transverse axis were measured to calculate the shape index. Three eggs were withdrawn from each treatment after pre-incubation, coverage, and storage to study the effect of the three factors (individually and interaction) on the egg quality. In addition, all eggs were weighed at days 1, 7, 15, and 18 of incubation to evaluate the effect of coverage, storage, and 
pre-incubation on egg weight and moisture loss. The hatchability and egg characteristics were measured after it was placed in the refrigerator for 24 hours. Therefore, the egg contents remained steady, in order for the thick albumin to take a full gelatinous texture, so measuring its high would be easy. Thereafter, the eggs were weighed individually and then broken on a flat glass surface with a bottom mirror in it to measure all the qualitative characteristics of the eggs, including yolk traits and shell traits according to the method suggested by Al-Fayadh et al., (2011). Shell weight per unit surface area (SWUSA) was measured according to the equation presented by Nordstrom and Ousterhout (1982) and derived from Carter (1975).

$$
\text { SWUSA }=\frac{\text { shell weight }(\mathrm{mg})}{3.9782 \times(\mathrm{egg} \text { weight }(\mathrm{mg}))^{0.7056}}
$$

Moreover, the percentage of egg weight loss was calculated through the equation mentioned by Zang et al. (2019).

\section{Statistical analysis}

Data were analyzed by three-way analysis of variance, as the first factor included the effect of the two coverage treatments, the second factor included the effect of the two storage treatments, and the third factor included the effect of pre-incubation treatments using the general linear model (GLM) procedures of SAS. The significant differences among the means were tested by Duncan's multiple range test at probability value $(\mathrm{p}<0.05$, Duncan, 1955).

\section{RESULTS AND DISCUSSION}

The results described in Table 1 indicated that the hatchability from fertile eggs significantly increased $(\mathrm{p}<$ $0.05)$ in covered eggs, compared to uncovered eggs. and there were no significant differences $(p<0.05)$ in the SWUSA, thickness of the shell, relative weight of the shell, and the shape index, whether between the two coverage treatments, between the two storage treatments, and between the pre-incubation treatments. The interactions between each of two factors or between the three factors indicated no significant differences.

Table 2 indicates that the seven-day egg storage period significantly reduced the yolk high and the yolk index, compared to the four-day egg storage period ( $\mathrm{p} \leq$ 0.05). Nevertheless, the yolk high and yolk index were not affected by coverage and pre-incubation. Moreover, haugh unit, relative weight of yolk and albumin, albumin high, and albumin index were not affected by any of the three factors individually. However, the results of interaction between coverage factor and pre-incubation factor were recorded the highest significant increase $(\mathrm{p}<0.05)$ in albumin high in eggs covered and incubated for 8 hours ( $p$ $<0.05)$.

Table 1. Effect of coverage, storage, and pre-incubation in Hatchability and Shell characteristics of broiler breeder (Ross, 308) eggs

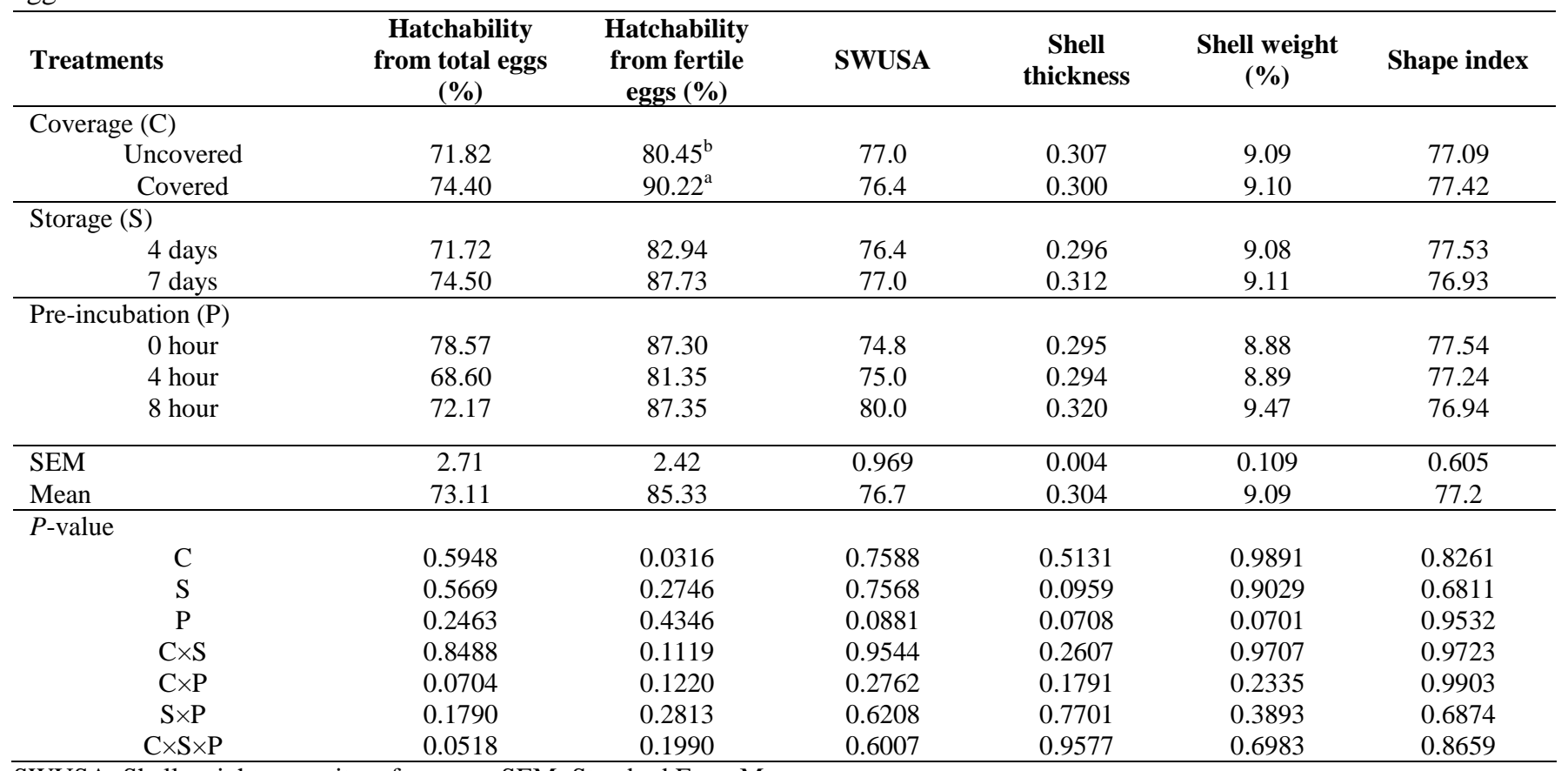

SWUSA: Shell weight per unit surface area. SEM: Standard Error Mean 
Table 2. Effect of coverage, storage, and pre-incubation in broiler breeder (Ross, 308) eggs characteristics

\begin{tabular}{|c|c|c|c|c|c|c|c|}
\hline Treatments & Haugh unit & $\begin{array}{c}\text { Albumin } \\
\text { weight }(\%)\end{array}$ & $\begin{array}{c}\text { Yolk } \\
\text { weight \% }\end{array}$ & $\begin{array}{c}\text { Albumin } \\
\text { high }\end{array}$ & $\begin{array}{l}\text { Yolk } \\
\text { high }\end{array}$ & $\begin{array}{l}\text { Albumin } \\
\text { index }\end{array}$ & $\begin{array}{c}\text { Yolk } \\
\text { index }\end{array}$ \\
\hline \multicolumn{8}{|l|}{ Coverage (C) } \\
\hline Covered & 62.71 & 57.2 & 28.3 & 4.46 & 16.0 & 27.9 & 0.396 \\
\hline \multicolumn{8}{|l|}{ Storage (S) } \\
\hline \multicolumn{8}{|l|}{ Pre-incubation (P) } \\
\hline 0 hour & 59.60 & 57.3 & 28.2 & 4.20 & 15.8 & 27.6 & 0.395 \\
\hline 4 hour & 60.76 & 57.8 & 28.4 & 4.30 & 16.3 & 28.4 & 0.404 \\
\hline 8 hour & 60.02 & 56.4 & 28.8 & 4.37 & 16.4 & 28.9 & 0.404 \\
\hline $\mathrm{C}$ & 0.0596 & 0.8745 & 0.7522 & 0.0855 & 0.3989 & 0.5676 & 0.3379 \\
\hline S & 0.2913 & 0.9705 & 0.4834 & 0.4950 & 0.0009 & 0.9682 & 0.0008 \\
\hline $\mathrm{P}$ & 0.7926 & 0.5751 & 0.8242 & 0.6682 & 0.1014 & 0.7427 & 0.5624 \\
\hline $\mathrm{C} \times \mathrm{S}$ & 0.1792 & 0.5925 & 0.7830 & 0.2582 & 0.0054 & 0.8370 & 0.0063 \\
\hline $\mathrm{C} \times \mathrm{P}$ & 0.0621 & 0.8083 & 0.5577 & 0.0489 & 0.2519 & 0.1901 & 0.6896 \\
\hline $\mathrm{S} \times \mathrm{P}$ & 0.1811 & 0.5943 & 0.5134 & 0.2821 & 0.3584 & 0.5339 & 0.2373 \\
\hline $\mathrm{C} \times \mathrm{S} \times \mathrm{P}$ & 0.0051 & 0.9325 & 0.4801 & 0.0007 & 0.1893 & 0.0008 & 0.6073 \\
\hline
\end{tabular}

SEM: Standard Error Mean, ${ }^{a, b, c,}$ : means in the same columns with different superscripts differ significantly at probability value $(\mathrm{p}<0.05)$

Table 3. Effect of coverage, storage, and pre-incubation in weight loss of broiler breeder (Ross, 308) eggs

\begin{tabular}{|c|c|c|c|c|c|}
\hline \multirow{2}{*}{ Treatments } & \multirow{2}{*}{$\begin{array}{l}\text { Initial egg weight } \\
\text { (gm) }\end{array}$} & \multicolumn{4}{|c|}{ Percentage of moisture loss during incubation $(\%)$} \\
\hline & & 1 day & 7 days & 15 days & 18 days \\
\hline \multicolumn{6}{|l|}{ Coverage $(\mathrm{C})$} \\
\hline Uncovered & 62.03 & $1.12^{\mathrm{a}}$ & $4.57^{\mathrm{a}}$ & 9.84 & 11.8 \\
\hline Covered & 60.16 & $0.749^{\mathrm{b}}$ & $4.18^{\mathrm{b}}$ & 9.34 & 11.1 \\
\hline \multicolumn{6}{|l|}{ Storage $(\mathrm{S})$} \\
\hline 4 days & 60.70 & 0.89 & 4.31 & 9.44 & 11.4 \\
\hline 7 days & 61.70 & 0.97 & 4.45 & 9.74 & 11.5 \\
\hline \multicolumn{6}{|l|}{ Pre-incubation $(\mathrm{P})$} \\
\hline 0 hour & 60.91 & 0.81 & 4.19 & 9.17 & 11.5 \\
\hline 4 hour & 61.38 & 1.04 & 4.57 & 10.00 & 11.6 \\
\hline 8 hour & 61.29 & 0.95 & 4.39 & 9.61 & 11.3 \\
\hline SEM & 0.653 & 0.0546 & 0.0813 & 0.160 & 0.201 \\
\hline Mean & 61.18 & 0.936 & 4.38 & 9.59 & 11.5 \\
\hline \multicolumn{6}{|l|}{$P$-value } \\
\hline $\mathrm{C}$ & 0.1850 & 0.0006 & 0.0149 & 0.1108 & 0.0580 \\
\hline $\mathrm{S}$ & 0.4474 & 0.4369 & 0.4105 & 0.3377 & 0.9343 \\
\hline $\mathrm{P}$ & 0.9625 & 0.2077 & 0.1555 & 0.0973 & 0.8759 \\
\hline $\mathrm{C} \times \mathrm{S}$ & 0.4782 & 0.0057 & 0.0831 & 0.2593 & 0.1521 \\
\hline $\mathrm{C} \times \mathrm{P}$ & 0.7357 & 0.2806 & 0.3464 & 0.2006 & 0.6378 \\
\hline $\mathrm{S} \times \mathrm{P}$ & 0.4600 & 0.1697 & 0.0821 & 0.0374 & 0.6183 \\
\hline $\mathrm{C} \times \mathrm{S} \times \mathrm{P}$ & 0.2864 & 0.1297 & 0.0166 & 0.0395 & 0.0482 \\
\hline
\end{tabular}

SEM: Standard Error Mean. ${ }^{\mathrm{a}, \mathrm{b}, \mathrm{c}}$ in the same column with different superscripts differ significantly at the level of $\mathrm{p}<0.05$ 
As for the results of the three factors interaction, the highest significant value $(\mathrm{p}<0.05)$ was for haugh unit and albumin high in covered eggs, stored for 7 days, and preincubated for 8 hours $(\mathrm{p}<0.05)$. On the other hand, uncovered eggs, stored for 7 days and pre-incubated for 8 hours, as well as covered eggs, stored for 7 days, which had not been subjected to pre-incubation, recorded a significant increase $(\mathrm{p} \leq 0.05)$ in the albumin index.

The percentage of moisture loss was calculated during the egg incubation period (18 days) decreased significantly $(p<0.05)$ at the first and seventh days of egg incubation in the covered eggs during the storage period, compared to the uncovered eggs during the storage period (Table 3). In addition, the results of the interaction between the coverage and storage factors indicated that the lowest significant percentage of moisture loss on the first day of incubation was in the covered and stored eggs for 4 days $(\mathrm{p}<0.05)$. As for the interaction between storage and preincubation factor, the lowest significant percentage of moisture loss was on day 15 in eggs that were stored for 4 days and were not subjected to pre-incubation $(\mathrm{p}<0.05)$. The same applies to the interaction of the three factors, as the covered eggs, stored for 4 days, which were not subjected to pre-incubation, recorded the lowest significant percentage of moisture loss on days 7,15 , and 18 of incubation ( $\mathrm{p}<0.05)$.

The results of this study were in accordance with the results of a study by Günhan and Kırıç̧ı (2017) revealing that the shell thickness and the shell weight were not affected by the length of the storage period. It was also indicated that the length of the storage period led to a significant decrease in the yolk index. Jin et al. (2011) found a significant decrease in the haugh unit and relative weight of the shell and albumin, and a significant increase in the $\mathrm{pH}$ of albumin and yolk when eggs were stored for 10 days at different temperatures. The decrease in the yolk index of eggs subjected to longer storage may be due to the transfer of water from the albumin to the yolk during storage. On the contrary, the transfer of free amino acids from the yolk to the albumin through the membrane of yolk leads to a decrease in the concentration of solid materials in the yolk. The transfer of water and nutrients between yolk and albumin is linked to an increase in the $\mathrm{pH}$ that leads to a weakening of the yolk membrane and an increase in its permeability of water and nutrients (Heath, 1975; Nasri et al., 2020). The perivitelline layer in the yolk sac became thinner and more elastic because it lost some of its components leading to the reduction of the yolk index. This disadvantage results from prolonged storage time (Fasenko et al., 1995; Brake et al., 1997).

Branum et al. (2016) indicated that there was a significant correlation between length of storage time and loss of moisture from the egg. The highest percentage of moisture loss during storage was for eggs stored for 12 days, compared to eggs stored for 3,5 , and 8 days, also the percentage of moisture loss for eggs that pre-incubated six hours was higher than eggs that did not pre-incubated (Reijrink et al., 2009). Fasenko et al. (2001) also explained that the interaction between storage and pre-incubation factors increases the weight loss of eggs after storage, as the highest percentage of weight loss was in the preincubated eggs for 18 hours, stored for 14 days during the storage period, and that the lowest percentage of weight loss was in eggs four-day stored that were not preincubated. The findings of a study by Fasenko et al. (2001) partly agreed with the current results indicating that the longer the period of storage and the more the hours of preincubation, the higher the percentage of weight loss. Long exposure to storage and pre-incubation can increase the process of evaporation of water from the eggs (Fasenko et al., 2001). The highest moisture loss during storage is for albumin because it contains the largest percentage of moisture in the egg, compared to the other parts of the egg, so the loss of moisture leads to shrinkage of the internal contents of the egg and a decrease in its weight (Reijrink, 2010).

The results of the weight loss percentage regarding egg coverage were in agreement with the results of Becker (1964), indicating that keeping the hatching eggs in Cryovac or polyethylene bags significantly reduced the percentage of weight loss when storing eggs for 15 days. Meyer and Spencer (1973) also found that coating of eggs with Epolene wax, polyvinylidene chloride, and acrylic resin significantly reduced moisture loss with eggs that were not coated. Davis and Beeckler (1962) found that the best coverage method to preserve moisture and $\mathrm{CO}_{2}$ is Cryovac bags. Nevertheless, Proudfoot (1964) did not find a significant effect of coverage during storage in the percentage of moisture loss.

The long storage periods led to a decrease in the quality of eggs, so that the use of plastic coverage can enhance the hatchability. Improving hatchability using covering comes from reducing water and $\mathrm{CO}_{2}$ loss (Mayes and Takeballi, 1984). Otherwise, uncovered eggs would evaporate their contents of $\mathrm{H}_{2} \mathrm{O}$ and $\mathrm{CO}_{2}$ which lead to an increased $\mathrm{pH}$ of albumin. It can be concluded that the hatchability may be improved by covering because of 
maintaining the stability of temperature as well $\mathrm{H}_{2} \mathrm{O}$ and $\mathrm{CO}_{2}$ levels (Becker, 1964). Regardless of the type of bags used to preserve the eggs, the gaseous environment provided by the coverage plays a role in improving the hatchability, and the packaging eggs in plastic bags recorded a lower level of albumin high. However, the most significant negative impact of coverage is the growth of molds due to the high humidity of the covered eggs. To overcome this problem, some researchers suggested adding a desiccant, such as silica gel, $\mathrm{CaCl}_{2}$, and sawdust to reduce the humidity. The other suggested operations are cleaning the eggs and collecting the eggs that will be covered later from a clean and dry litter before coverage to reduce the chances of contamination, in addition to cooling the eggs (Becker et al., 1964).

The use of egg coverage is more feasible in older broiler breeders, as the functional properties of cuticle change with the aging of the broiler breeders, and their ability to water loss would be increased (Peebles and Brake, 1986) as that young broiler breeders produce thicker shells and have longer pores, compared to the shells produced by older broiler breeders. The shell is thinner as a result of age progression, but it may be thick if the egg production decreases relative to the calcium intake (Peebles and Brake, 1987). The quality of the shell, determined by the number and size of the pores in addition to the thickness of the shell, affects moisture loss as well as the activity of the embryo and the amount of moisture in the external environment of the egg (Bergoug et al., 2013).

\section{CONCLUSION}

In conclusion, the hatching eggs coverage during storage reduced the negative effect of storage by decreasing moisture loss. Consequently, the quality of the yolk was degraded when the storage period was prolonged. However, the shell characteristics were not affected by study factors individually or in interaction. Furthermore, the interaction between coverage factor and pre-incubation factor indicated the highest significant increase in albumin high for eggs covered and pre-incubated for 8 hours.

\section{DECLARATION}

\section{Acknowledgments}

We would like to recognize the invaluable assistance of our colleague Dr. Bilal J M Aldahham. And we are grateful to the Management and staff of the commercial
Alfurat hatchery, for the support provided to complete this research.

\section{Competing interests}

Ezzat K. I. Al-Samrai and Ammar A. Tawfeeq declare that they have no conflict of interest.

\section{Authors' contribution}

All authors contributed equally in present study.

\section{Ethical considerations}

Ethical issues (including plagiarism, consent to publish, misconduct, data fabrication and/or falsification, double publication and/or submission, and redundancy) have been checked by the authors.

\section{REFERENCES}

Al-Fayadh HA, Naji SA, and Al-Hajo NNA (2011). Poultry product technology (part one). $2^{\text {nd }}$ Edition, Directorate of Ministry of Higher Education and Scientific Research Press, Baghdad, Iraq.

Al-Samrai EK (2012). Effect of pre-incubation and storage of hatching eggs on hatchability, performance and physiological of broiler. Master Thesis. College of Agriculture, University Of Anbar, Anbar, Iraq.

Becker WA (1964). The storage of White Leghorn hatching eggs in plastic bags. Poultry Science, 43(5): 1109-1112. https://doi.org/10.3382/ps.0431109

Becker WA, Spencer JV, and Swartwood JL (1964). The pre-incubation storage of turkey eggs in closed environments. Poultry Science, 43(6): 1526-1534. https://doi.org/10.3382/ps.0431526

Bergoug H, Burel C, Guinebretiere M, Tong Q, Roulston N, Romanini CEB, and Bahr C (2013). Effect of pre-incubation and incubation conditions on hatchability, hatch time and hatch window, and effect of post-hatch handling on chick quality at placement. World's Poultry Science Journal, 69(2): 313-334. https://doi.org/10.1017/S0043933913000329

Bloom SE, Muscarella DE, Lee MY, and Rachlinski M (1998). Cell death in the avian blastoderm: Resistance to stress-induced apoptosis and expression of anti-apoptotic genes. Cell Death and Differentiation, 5(6): 529-538. https://doi.org/10.1038/sj.cdd.4400381

Brake J, Walsh TJ, Benton CE, Petitte JN, Meijerhof R, and Penalva G (1997). Egg handling and storage. Poultry Science, 76(1): 144-151. https://doi.org/10.1093/ps/76.1.144

Branum SR, Tazawa H, and Burggren WW (2016). Phenotypic developmental plasticity induced by preincubation egg storage in chicken embryos (Gallus gallus domesticus). Physiological Reports, 4(4): e12712, 1-17. https://doi.org/10.14814/phy2.12712

Butler DE (1990). Egg handling and storage at the farm and hatchery. In Avian Incubation, (SG Tullett, ed.), pp. 195-203. London, Butterworth. https://www.cabdirect.org/cabdirect/abstract/19910189297

Carter T (1975). The hen's egg: Estimation of shell superficial area and egg volume, using measurements of fresh egg weight and shell length and breadth alone or in combination. British Poultry Science, 16(5): 541-543. https://doi.org/10.1080/00071667508416224

Davis GT, and Beeckler AFJPS (1962). Plastic packaging of eggs: 1. methods of packaging. Poultry Science, 41: 391-397. https://doi.org/10.3382/ps.0410391 
Duncan DBJB (1955). Multiple range and multiple F tests. Biometrics, 11(1): 1-42. https://doi.org/10.2307/3001478

Fasenko GM, Christensen VL, Bakst MR, and Petitte JN (1995). Evaluating yolk membranes from short and long stored turkey eggs using transmission electron microscopy. Poultry Science, 74 (Suppl. 1): 44.

Fasenko GM, Robinson FE, Whelan AI, Kremeniuk KM, and Walker JA (2001). Prestorage incubation of long-term stored broiler breeder eggs: 1. Effects on hatchability. Poultry Science, 80(10): 14061411. https://doi.org/10.1093/ps/80.10.1406

Fasenko GM (2007). Egg storage and the embryo. Poultry science, 86(5): 1020-1024. https://doi.org/10.1093/ps/86.5.1020

Günhan Ş, and Kırıkçı K (2017). Effects of different storage time on hatching results and some egg quality characteristics of rock partridge (A. graeca) (management and production). Poultry Science, 96(6): 1628-1634. https://doi.org/10.3382/ps/pew443

Heath JL (1975). Investigation of changes in yolk moisture. Poultry Science, 54(6): 2007-2014. https://doi.org/10.3382/ps.0542007

Jin YH, Lee KT, Lee WI, and Han YK (2011). Effects of storage temperature and time on the quality of eggs from laying hens at peak production. Asian-Australasian Journal of Animal Sciences, 24(2): 279-284. https://doi.org/10.5713/ajas.2011.10210

Khan MJ, Khan SH, Bukhsh A, and Amin M (2014). The effect of storage time on egg quality and hatchability characteristics of Rhode Island Red (RIR) hens. Veterinarski Arhiv , 84: 291-303. http://citeseerx.ist.psu.edu/viewdoc/download?doi=10.1.1.644.590 $\underline{\& \text { rep }=\text { rep } 1 \& \text { type }=\text { pdf }}$

Kollmann Filho J, Zampar A, Boiago MM, and Da Silva AS (2020). Effect of heat treatment on pre-stocking of Turkey eggs and its impact on incubation and hatching. Journal of Thermal Biology, 88: 102501. https://doi.org/10.1016/j.jtherbio.2019.102501

Mather CM, and Laughlin K (1979). Storage of hatching eggs: The interaction between parental age and early embryonic development.

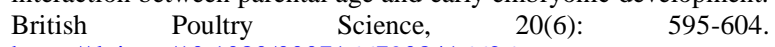
https://doi.org/10.1080/00071667908416626

Mayes FJ, and Takeballi MA (1984). Storage of the eggs of the fowl (Gallus domesticus) before incubation: A review. World's Poultry $\begin{array}{lll}\text { Science Journal, } & \text { 40(2): }\end{array}$ https://doi.org/10.1079/WPS19840011

Meijerhof R (1992). Pre-incubation holding of hatching eggs. World's $\begin{array}{llll}\text { Poultry Science } & \text { Journal, } & \text { 48(1): }\end{array}$ https://doi.org/10.1079/WPS19920006

Meyer R, and Spencer JV (1973). The effect of various coatings on shell strength and egg quality. Poultry Science, 52(2): 703-711. https://doi.org/10.3382/ps.0520703

Nasri H, Van den Brand H, Najjar T, and Bouzouaia M (2020). Egg storage and breeder age impact on egg quality and embryo development. Journal of Animal Physiology and Animal Nutrition, 104(1): 257-268. https://doi.org/10.1111/jpn.13240

Nordstrom, JO, and Ousterhout, LE. (1982). Estimation of shell weight and shell thickness from egg specific gravity and egg weight. $\begin{array}{lll}\text { Poultry Science, } & 61(10), & 1991-1995 .\end{array}$ https://doi.org/10.3382/ps.0611991
Özlü S, Uçar A, Erkuş T, Yasun S, Nicholson AD, and Elibol O. (2021). Effects of flock age, storage temperature, and short period of incubation during egg storage, on the albumen quality, embryonic development and hatchability of long stored eggs. British Poultry Science, 62(4): 611-619. https://doi.org/10.1080/00071668.2021.1887454

Peebles ED, and Brake J (1986). The role of the cuticle in water vapor conductance by the eggshell of broiler breeders. Poultry Science, 65(6): 1034-1039. https://doi.org/10.3382/ps.0651034

Peebles ED, Brake J (1987). Eggshell quality and hatchability in broiler breeder eggs. Poultry Science, 66(4): 596-604. https://doi.org/10.3382/ps.0660596

Proudfoot FG, and Hamilton RMG (1990). Care of hatching eggs before incubation. Publication 1573/E, Communications Branch, Agriculture Canada, Ottawa, ON, Canada. https://doi.org/10.5962/bhl.title.59097

Proudfoot FG (1964). The effects of plastic packaging and other treatments on hatching eggs. Canadian Journal of Animal Science, 44(1): 87-95. https://doi.org/10.4141/cjas64-013

Reijrink IAM (2010). Storage of hatching eggs: Effects of storage and early incubation conditions on egg characteristics, embryonic development, hatchability, and chicken quality. PhD Thesis, Wageningen University, Netherland. https://library.wur.nl/WebQuery/wurpubs/fulltext/139676

Reijrink IAM, Meijerhof R, Kemp B, Graat EAM, and van den Brand H (2009). Influence of prestorage incubation on embryonic development, hatchability, and chick quality. Poultry Science, 88(12): 2649-2660. https://doi.org/10.3382/ps.2008-00523

Rocha JSR, Baiao NC, Barbosa VM, Pompeu MA, Fernandes MNS, Lara LJC, and Batista JVM (2013). Negative effects of fertile egg storage on the egg and the embryo and suggested hatchery management to minimise such problems. World's Poultry Science Journal, 69(1): 35-44. https://doi.org/10.1017/S0043933913000044

Ruiz J, and Lunam CA (2002). Effect of pre-incubation storage conditions on hatchability, chick weight at hatch and hatching time in broiler breeders. British Poultry Science, 43(3): 374-383. https://doi.org/10.1080/00071660120103648

Samli HE, Agma A, and Senkoylu N (2005). Effects of storage time and temperature on egg quality in old laying hens. Journal of Applied $\begin{array}{lll}\text { Poultry } & \text { Research, } & 14(3) \text { : }\end{array}$ https://doi.org/10.1093/japr/14.3.548

Tesarova MP, Skoupa M, Foltyn M, Tvrdon Z, and Lichovnikova M. (2021). Research Note Effects of preincubation and higher initiating incubation temperature of long-term stored hatching eggs on hatchability and day-old chick and yolk sac weight. Poultry Science, 100(8): 101293. https://doi.org/10.1016/j.psj.2021.101293

van den Brand H, Reijrink IAM, Hoekstra LA, and Kemp B (2008). Storage of eggs in water affects internal egg quality, embryonic development, and hatchling quality. Poultry Science, 87(11): 23502357. https://doi.org/10.3382/ps.2007-00451

Zang YT, Bing S, Li YJ, Shu DQ, Huang AM, Wu HX, and Wu HD (2019). Efficacy of slightly acidic electrolyzed water on the microbial safety and shelf life of shelled eggs. Poultry Science, 98(11): 5932-5939. https://doi.org/10.3382/ps/pez373 